\title{
Interpolational $(L, M)$-rational integral fraction on a continual set of nodes
}

\author{
Baranetskij Ya.O. ${ }^{1}$, Demkiv I.I. ${ }^{1}$, Kopach M.I. ${ }^{2}$, Solomko A.V. ${ }^{2}$
}

In the paper, an integral rational interpolant on a continual set of nodes, which is the ratio of a functional polynomial of degree $L$ to a functional polynomial of degree $M$, is constructed and investigated. The resulting interpolant is one that preserves any rational functional of the resulting form.

Key words and phrases: interpolation, functional polynomial, continual set of nodes, chain fraction, rational fraction.

\footnotetext{
${ }^{1}$ Lviv Polytechnic National University, 12 Bandera str., 79013, Lviv, Ukraine

2 Vasyl Stefanyk Precarpathian National University, 57 Shevchenka str., 76018, Ivano-Frankivsk, Ukraine

E-mail: baryaromeukr.net (Baranetskij Ya.O.), ihor.i.demkivelpnu.ua (Demkiv I.I.), kopachm2009@gmail.com (Kopach M.I.), ansolvas@gmail.com (Solomko A.V.)
}

\section{Introduction}

A lot of papers are devoted to problem of approximation of functionals $F: L_{1}(0,1) \rightarrow \mathbb{R}^{1}$ on a continual set of nodes

$$
\begin{gathered}
x^{n}\left(z, \xi^{n}\right)=x_{0}(z)+\sum_{i=1}^{n} H\left(z-\xi_{i}\right)\left[x_{i}(z)-x_{i-1}(z)\right], \\
\xi^{n}=\left(\xi_{1}, \xi_{2}, \ldots, \xi_{n}\right) \in \Omega_{z^{n}}=\left\{z^{n}: 0 \leq z_{1} \leq \ldots \leq z_{n} \leq 1\right\},
\end{gathered}
$$

for example, see $[1-10,12]$.

Let $x_{i}(z) \in Q[0,1], i=0,1, \ldots$, be arbitrary fixed elements of the space $Q[0,1]$ of piecewise continuous functions on the segment $[0,1]$ with a finite number of discontinuity points of the first kind. The set of such functions is called the interpolant framework. Let $H(t)$ be the Heaviside function.

In the papers [1,2], the approximation of the Urisohn operator by polynomials of Bernsteintype and Stancu-type is investigated. In the papers [3-5], the polynomial approximation of functionals is researched. The works [6-10] are devoted to the representation of functionals by chain fractions.

To simplify a notation of a finite chain fraction we use the following notes

$$
\frac{a_{1}}{b_{1}+\frac{a_{2}}{b_{2}+\frac{a_{3}}{b_{3}+\ddots+\frac{a_{n}}{b_{n}}}}}=\prod_{i=1}^{n} \frac{a_{i}}{b_{i}}=\frac{a_{1} \mid}{\mid b_{1}}+\frac{a_{2} \mid}{\mid b_{2}}+\ldots+\frac{a_{n} \mid}{\mid b_{n}} .
$$

$\mathrm{y} \Delta \mathrm{K} 519.65$

2010 Mathematics Subject Classification: 40A15, 41A05, 41A10. 
Note, that using of the formula (2) both for practical calculations and for theoretical research is quite inconvenient. Therefore, it will be useful its transformation (see [11, p. 40]).

Lemma 1. nth suitable fraction

$$
Q_{n}=q_{0}+\prod_{i=1}^{n} \frac{q_{i}}{1}
$$

of continued fraction $Q_{\infty}$ coincides with the fraction $Q_{n}=A_{n} / B_{n}$, where $n$th numerator $A_{n}$ and $n$th denominator $B_{n}$ are determined by recurrent formulas

$$
\begin{array}{cccc}
A_{k}=A_{k-1}+q_{k} A_{k-2}, & k=1,2, \ldots, & A_{-1}=1, & A_{0}=K_{0}^{I}, \\
B_{k}=B_{k-1}+q_{k} B_{k-2}, & k=1,2, \ldots, & B_{-1}=0, & B_{0}=1 .
\end{array}
$$

Note, if $q_{i}=q_{i}(x(\cdot)), i=0,1, \ldots, n$, are defined by formula (2), then $A_{n}, B_{n}$ are the functional polynomials of variable $x(z)$ of $[(n+1) / 2][(n+2) / 2]$ th and $[n / 2][(n+3) / 2]$ th degrees respectively and $Q_{n}(x(\cdot))$ is rational functional interpolant. Here and subsequently, square brackets denote the integer part of a real. However, the total functional degree of the numerator and denominator is $[(n+1) / 2][(n+2) / 2]+[n / 2][(n+3) / 2]$, and the number of nodes in the framework of continuous interpolation nodes is equal to $n+1$.

\section{Formulation of the problem and solution}

Let us consider the problem of constructing an approximation rational fraction for the functional $F: L_{1}(0,1) \rightarrow \mathbb{R}^{1}$.

We can find a rational interpolation functional fraction in the following form

$$
R_{l, m}(x(\cdot))=\frac{A_{l}(x(\cdot))}{B_{m}(x(\cdot))}
$$

where

$$
\begin{gathered}
A_{l}(x(\cdot))=F\left(x_{0}(\cdot)\right)+\sum_{j=1}^{l} \int_{0}^{1} \int_{z_{1}}^{1} \ldots \int_{z_{j-1}}^{1} K_{1, j}^{I}\left(z^{j}\right) \prod_{p=1}^{j}\left(x\left(z_{p}\right)-x_{p-1}\left(z_{p}\right)\right) d z_{j} \ldots d z_{1}, \\
B_{m}(x(\cdot))=1+\sum_{j=1}^{m} \int_{0}^{1} \int_{z_{1}}^{1} \ldots \int_{z_{j-1}}^{1} K_{2, j}^{I}\left(z^{j}\right) \prod_{p=1}^{j}\left(x\left(z_{p}\right)-x_{p-1}\left(z_{p}\right)\right) d z_{j} \ldots d z_{1} .
\end{gathered}
$$

In the general case, all kernels $K_{1, j}^{I}\left(z^{j}\right)$ and $K_{2, j}^{I}\left(z^{j}\right)$ should be found from interpolation conditions. However, we will do otherwise. First, we consider the following theorem from [12].

Theorem 1. In order for the functional $F: L_{1}(0,1) \rightarrow \mathbb{R}^{1}$ to have a representation

$$
F(x(\cdot))=F\left(x_{0}(\cdot)\right)+\sum_{j=1}^{n} \int_{0}^{1} \int_{z_{1}}^{1} \ldots \int_{z_{j-1}}^{1} K_{j}^{I}\left(z^{j}\right) \prod_{p=1}^{j}\left(x\left(z_{p}\right)-x_{p-1}\left(z_{p}\right)\right) d z_{j} \ldots d z_{1}+R_{n}(x(\cdot)),
$$

it is necessary and sufficient to satisfy the substitution rule

$$
\begin{aligned}
& \frac{\partial^{p}}{\partial z_{1} \partial z_{2} \ldots \partial z_{p}}\left[\left.F\left(x^{p+1}\left(\cdot ; z^{p+1}\right)\right)\right|_{z_{p+1}=z_{p}}\right] \\
& \quad=\left.\left[\frac{\partial^{p}}{\partial z_{1} \partial z_{2} \ldots \partial z_{p}} F\left(x^{p+1}\left(\cdot ; z^{p+1}\right)\right)\right]\right|_{z_{p+1}=z_{p}} \frac{x_{p+1}\left(z_{p}\right)-x_{p-1}\left(z_{p}\right)}{x_{p}\left(z_{p}\right)-x_{p-1}\left(z_{p}\right)}, \quad p=1, \ldots, n,
\end{aligned}
$$


where the kernels are defined by formulas

$$
K_{j}^{I}\left(z^{j}\right)=(-1)^{j} \prod_{p=1}^{j}\left(x_{p}\left(z_{p}\right)-x_{p-1}\left(z_{p}\right)\right)^{-1} \frac{\partial^{j} F\left(x^{j}\left(\cdot ; z^{j}\right)\right)}{\partial z_{1} \ldots \partial z_{j}}, \quad j=1, \ldots, n,
$$

and residue has the following form

$$
\begin{aligned}
R_{n}(x(\cdot))=(-1)^{n+1} \int_{0}^{1} & \int_{z_{1}}^{1} \ldots \int_{z_{n}}^{1} \frac{\partial^{n+1} F\left(x^{n+1}\left(\cdot ; z^{n+1}\right)\right)}{\partial z_{1} \partial z_{2} \ldots \partial z_{n+1}} \\
& \times \prod_{p=1}^{n} \frac{\left(x\left(z_{p}\right)-x_{p-1}\left(z_{p}\right)\right)}{\left(x_{p}\left(z_{p}\right)-x_{p-1}\left(z_{p}\right)\right)} d z_{n+1} d z_{n} \ldots d z_{1}, \quad x_{n+1}(z)=x(z) .
\end{aligned}
$$

Let us consider the case, when $l \leq m$ and $A_{l}(x(\cdot))$ from (4) coincides with the polynomial expansion of the functional $F(x(\cdot))$ from (6) and the kernels $K_{1, j}^{I}\left(z^{j}\right)$ are defined by formulas (8). In this case we can find the residue by formula (9) and the substitution rule (7) holds.

To find the kernels $K_{2, j}^{I}\left(z^{j}\right)$ from (5) we can use the interpolation conditions

$$
R_{l, m}\left(x^{j}\left(\cdot ; z^{j}\right)\right)=F\left(x^{j}\left(\cdot ; z^{j}\right)\right), \quad j=1,2, \ldots, m,
$$

where $x^{j}\left(t ; z^{j}\right)=x_{0}(t)+\sum_{p=1}^{j} H\left(t-z_{p}\right)\left[x_{p}(t)-x_{p-1}(t)\right], j=1,2, \ldots, m$.

Thus, we obtain the kernel

$$
K_{2, j}^{I}\left(z^{j}\right)=(-1)^{j} \prod_{p=1}^{j}\left(x_{j}\left(z_{p}\right)-x_{p-1}\left(z_{p}\right)\right)^{-1} \frac{\partial^{j}}{\partial z_{1} \ldots \partial z_{j}} \frac{A_{l}\left(x^{j}\left(\cdot ; z^{j}\right)\right)}{F\left(x^{j}\left(\cdot ; z^{j}\right)\right)} .
$$

Note, that from the Theorem 1 it follows that the equality

$$
\frac{\partial^{j}}{\partial z_{1} \ldots \partial z_{j}} \frac{A_{k}\left(x^{j}\left(\cdot ; z^{j}\right)\right)}{F\left(x^{j}\left(\cdot ; z^{j}\right)\right)}=0
$$

holds for all $j \leq k$. Therefore, the ratio (5) will have the following form

$$
B_{m}(x(\cdot))=1+\sum_{j=l+1}^{m} \int_{0}^{1} \int_{z_{1}}^{1} \ldots \int_{z_{j-1}}^{1} K_{2, j}^{I}\left(z^{j}\right) \prod_{p=1}^{j}\left(x\left(z_{p}\right)-x_{p-1}\left(z_{p}\right)\right) d z_{j} \ldots d z_{1} .
$$

In this case the following theorem holds.

Theorem 2. In order for there to be an unique rational interpolation functional (3), (4), (8), (10), (11), on a continual set of nodes (1)

$$
x^{j}\left(t ; z^{j}\right)=x_{0}(t)+\sum_{p=1}^{j} H\left(t-z_{p}\right)\left[x_{p}(t)-x_{p-1}(t)\right], \quad j=1,2, \ldots, m,
$$

it is necessary and sufficient for the functional $F(x(\cdot))$ to satisfy the substitution rule (7).

Note, that the interpolant (3), (4), (8), (10), (11) is the one that holds any rational functional of the form (3). 
Example. Let the functional $F(x(\cdot))$ has the form

$$
F(x(\cdot))=\operatorname{arctg} \int_{0}^{1} x(t) d t
$$

and $l=1, m=2$. Then from (3), (4) and (11) we obtain

$$
\begin{gathered}
x^{1}\left(z ; \xi_{1}\right)=x_{0}(z)+H\left(z-\xi_{1}\right)\left(x_{1}(z)-x_{0}(z)\right), \\
x^{2}\left(z ; \xi^{2}\right)=x_{0}(z)+H\left(z-\xi_{1}\right)\left(x_{1}(z)-x_{0}(z)\right)+H\left(z-\xi_{2}\right)\left(x_{2}(z)-x_{1}(z)\right), \\
R_{1,2}^{I}(x(\cdot))=\frac{A_{1}(x(\cdot))}{B_{2}(x(\cdot))}
\end{gathered}
$$

where

$$
\begin{gathered}
A_{1}(x(\cdot))=F\left(x_{0}(\cdot)\right)-\int_{0}^{1} \frac{d F\left(x^{1}\left(\cdot ; z^{1}\right)\right)}{d z} \frac{\left(x(z)-x_{0}(z)\right)}{\left(x_{1}(z)-x_{0}(z)\right)} d z, \\
B_{2}(x(\cdot))=1+\int_{0}^{1} \int_{0}^{1} \frac{\partial^{2}}{\partial z_{1} \partial z_{2}} \frac{A_{1}\left(x^{2}\left(\cdot ; z^{2}\right)\right)}{F\left(x^{2}\left(\cdot ; z^{2}\right)\right)} \prod_{i=1}^{2} \frac{\left(x\left(z_{i}\right)-x_{i-1}\left(z_{i}\right)\right)}{\left(x_{i}\left(z_{i}\right)-x_{i-1}\left(z_{i}\right)\right)} d z_{2} d z_{1} .
\end{gathered}
$$

Therefore, the rational interpolation functional fraction on a continual set of nodes $x^{2}\left(z ; \xi^{2}\right)$, $\xi^{2} \in \Omega_{2}$, is constructed for a functional $F(x(\cdot))$. For the framework of interpolation nodes we can take, for example, $x_{0}(t)=0, x_{1}(t)=t, x_{2}(t)=t^{2}$. Then it is easy to verify that

$$
\frac{d}{d \xi_{1}}\left[\left.F\left(x^{2}\left(\cdot ; \xi^{2}\right)\right)\right|_{\xi_{2}=\xi_{1}}\right]=\frac{-\xi_{1}^{2}}{1+\left(1 / 3-\xi_{1}^{3} / 3\right)^{2}},\left.\quad\left[\frac{\partial}{\partial \xi_{1}} F\left(x^{2}\left(\cdot ; \xi^{2}\right)\right)\right]\right|_{\xi_{2}=\xi_{1}}=\frac{-\xi_{1}}{1+\left(1 / 3-\xi_{1}^{3} / 3\right)^{2}}
$$

and the substitution rule holds. The results of the calculations we record in the Table 1, where $R_{1,2}^{I}(x(\cdot))$ is rational interpolation functional, and

$$
d=\operatorname{arctg} \int_{0}^{1} x(t) d t, \quad d P=R_{1,2}^{I}-d .
$$

\begin{tabular}{|c|c|c|}
\hline & $x(t)=\sqrt{t}$ & $x(t)=\sin (t)$ \\
\hline$R_{1,2}^{I}$ & 0.6179360142 & 0.4223479311 \\
$d$ & 0.5880026036 & 0.4308892024 \\
$d P$ & 0.0299334106 & 0.0085412713 \\
\hline
\end{tabular}

Table 1. The results of calculations.

\section{References}

[1] Demkiv I.I. On properties of Bernstein-type operator polynomials that approximate the Urysohn operator. Ukrainian Math. J. 2004, 56 (9), 1391-1402. doi:10.1007/s11253-005-0123-9 (translation of Ukrain. Mat. Zh. 2004, 56 (9), 1172-1181. (in Ukrainian))

[2] Demkiv I.I., Makarov V.L. Approximation of the Urysohn operator by operator polynomials of Stancu type. Ukrainian Math. J. 2012, 64 (3), 318-343. doi:10.1007/s11253-012-0652-y (translation of Ukrain. Mat. Zh. 2012, 64 (3), 318-343. (in Ukrainian)) 
[3] Demkiv I.I. Interpolation functional polynomial of the fourth order which does not use substitution rule. J. Numer. Appl. Math. 2010, 100 (1), 40-59.

[4] Demkiv I.I. An interpolation functional third-degree polynomial that does not use substitution rules. J. Math. Sci. 2012, 180 (1), 34-50. doi:10.1007/s10958-011-0627-9 (translation of Mat. Metody Fiz.-Mekh. Polya 2010, 53 (3), 46-59. (in Ukrainian))

[5] Baranetskij Y.O., Demkiv I.I., Kopach M.I., Obshta A.F. The interpolation functional polynomial: the analogue of the Taylor formula. Mat. Stud. 2018, 50 (2), 198-203. doi:10.15330/ms.50.2.198-203

[6] Makarov V.L., Demkiv I.I. Relation between interpolating integral continued fractions and interpolating branched continued fractions. J. Math. Sci. 2010, 165 (2), 171-180. doi:10.1007/s10958-010-9787-2 (translation of Mat. Metody Fiz.-Mekh. Polya 2008, 51 (3), 13-20. (in Ukrainian))

[7] Makarov V.L., Demkiv I.I. Interpolating integral continued fraction of the Thiele type. J. Math. Sci. 2017,220 (1), 50-58. doi:10.1007/s10958-016-3167-5 (translation of Mat. Metody Fiz.-Mekh. Polya 2014, 57 (4), 44-50. (in Ukrainian))

[8] Makarov V.L., Demkiv I.I. Abstract interpolating fraction of the Thiele type. J. Math. Sci. 2018, 231 (4), 536546. doi:10.1007/s10958-018-3832-y (translation of Mat. Metody Fiz.-Mekh. Polya 2016, 59 (2), 50-57. (in Ukrainian))

[9] Makarov V.L., Demkiv I.I. Abstract interpolation by continued Thiele-type fractions. Cybernet. Systems Anal. 2018, 54 (1), 122-129. doi:10.1007/s10559-018-0013-4

[10] Demkiv I., Ivasyuk I., Kopach M. Interpolation integral continued fraction with twofold node. Math. Model. Comput. 2019, 6 (1), 1-13. doi:10.23939/mmc2019.01.001

[11] Jones W.B., Thron W.J. Continued fractions: analytic theory and applications. Mir, Moscow, 1985. (in Russian)

[12] Makarov V.L., Demkiv I.I., Mykhalchuk B.R. Necessary and sufficient conditions for the existence of the functional interpolation polynomial on the continual set of interpolation nodes. Dopov. Nats. Akad. Nauk Ukr. 2003, (7), 7-12. (in Ukrainian)

Баранецький Я.О., Аемків I.I., Копач M.І., Соломко А.В. Інтерполячійний (L, M)-рачіональний інтегральний дріб на континуальній множині вузлів // Карпатські матем. публ. - 2021. — Т.13, №3. - С. 587-591.

У статті будується та досліджується інтегральний раціональний інтерполянт на континуальній множині вузлів, який $є$ відношенням функціонального полінома степеня $L$ до функціонального полінома степеня $M$. Одержаний інтерполянт є таким, що зберігає будь-який раціональний функціонал одержаного виглялу.

Ключові слова і фрази: інтерполяція, функціональний поліном, континуальна множина вузлів, ланцюговий дріб, раціональний дріб. 